\title{
ESTUDIO LLEVADO A CABO SOBRE REPRESENTACIONES DE LA RESPIRACIÓN CELULAR EN LOS ALUMNOS DE BACHILLERATO Y COU
}

\author{
GARCÍA ZAFORAS, A.M. \\ C.F.P. de Castilleja de la Cuesta. C/ Príncipe de Asturias, 26. \\ Castilleja de la Cuesta (Sevilla).
}

\section{SUMMARY}

This paper reports on an experiment involving students of the Natural Sciences and Biology subjects in first and third year BUP and COU. The experiment involved investigating the students' alternative ideas of cellular breathing and determining whether they evolve throughout the students' secondary education (BUP and COU).

\section{FUNDAMENTACIÓN}

Quizás influenciados por uná dogmatización de la Ciencia que adolece de poca investigación en el aula y dejándonos llevar por inercia del ritmo que imponen los libros de texto, del lenguaje cotidiano que a veces interfiere con el científico, junto a la metodología usada por la mayoría de nuestro profesorado, propiciamos toda una serie de elementos que inducen a los alumnos fre cuentemente a ideas conceptuales alternativas, siendo la investigación de algunas de ellas el objeto de este estudio.

Centrándonos en el campo de las Ciencias Naturales, e! concepto de que la vida de un organismo la mantiene el funcionamiento de sus células supone para la mayoría de nuestros alumnos un escalón difícil de entender, quizás por la poca estructuración con que se estudian los temas correspondientes al nivel orgánico y al nivel celular, o dicho de otra forma por la desvinculación que ofrecemos al alumno entre el mundo macroscópico y el microscópico, donde el primero encuentra su verdadera fundamentación fisiológica.

La mayoría de nuestros alumnos cree saber lo que son las funciones de nutrición, pero que el estudio de ellas englobe la respiración y eI oxígeno como nutriente, la circulación y la sangre como medio que transporta los nutrientes, la excreción que a su ve $z$ suelen confundir con egestión $\mathrm{y}$, aún más, que todos estos procesos tengan sus últimas consecuencias a nivel de las células -donde se lleva a cabo el metabolismo celular- supone un engranaje que a una mayoría de nuestros alumnos les cuesta llegar a entender; uniéndole, además, la falta de motivación de la que gozan, causada, entre otros factores, por el papel pasivo a que los sometemos y al excesivo protagonismo del profesor, ambiente en el que habitualmente se desarrolla nuestra enseñanza hoy día.

Concretemos más el tema mediante un ejemplo: por respiración entienden, nuestros alumnos, el simple intercambio de gases con el medio ambiente que se lleva a cabo con el aparato respiratorio y no van más allá en la cuestión, sin acabar de comprender que la verdadera respiración se lleva a cabo en cada una de nuestras células y que la función del aparato respiratorio es la de actuar de mero intermediario en todo el proceso de la respiración celular. Esto trae en consecuencia, errores conceptuales de grandes magnitudes, como es el caso de: ${ }_{i} \mathrm{Si}$ los vegetales carecen de aparato respiratorio que es el que lleva a cabo la respiración, pues será que no respiran!! Manifiestan así, según señalan Driver, Guesne y Tiberghien (1985), un razonamiento dominado por 
la percepción (los rasgos observables). Tampoco comprenden que el oxígeno sea un nutriente neccsario para la célula, pero que al ser gascoso se capta por distinta vía que los nutrientes líquidos y sólidos, aunque de igual manera que éstos su actuación se va a llevar a cabo en el seno de las células.

\section{OBJETIVO DE LA EXPERIENCIA}

Apoyándonos en la teoría ausubeliana, el aprenđizaje significativo se produce cuando los nuevos conocimientos conectan con las ideas previas que tienen los alumnos sobre el tema. El objetivo de esta experiencia es, pues, investigar y cuantificar la magnitud de las representaciones que poseen los alumnos (Driver, Guesne y Tiberghien 1985) sobre la función de respiración en los seres vivos, con vistas a provocar, si fuera necesario, el consabido cambio conceptual y metodológico que nos conduzca dentro de un paradigma constructivista a una enseñanza más racional y por tanto a un aprendizaje más significativo (Ausubel 1978).

\section{HIPÓTESIS}

«Los alumnos de bachillerato y COU que cursan estudios de Ciencias Naturales presentan ideas alternativas respecto a la respiración celular». El análisis del contraste de las respuestas dadas por los alumnos en los niveles de $1^{\prime \prime}, 3^{\circ}$ y $\mathrm{COU}$, nos permitirá observar la persistencia de estas representaciones (Furió, Carrascosa y Gil 1985).

\section{RECURSOS}

La estrategia utilizada para esta investigación ha consistido en la elaboración y contestación de encuestas, previamente comentadas y contrastadas por distintos profesores miembros del seminario didáctico. La muestra ha sido tomada en un solo centro, un instituto de bachillerato situado en zona urbana, donde predomina un alumnado de clase media-alta. Ha sido contestada por un alumnado no seleccionado, correspondiente a 50 alumnos de $1^{2}$ de BUP, 53 alumnos de $3^{\circ}$ de BUP y 49 alumnos de COU. En todos los casos estos alumnos habían estudiado ya los temas correspondientes a la nutrición celular. No hay que descartar, por tanto, que entre las respuestas correctas exista un porcentaje de lo que Hewson (1981), Ausubel (1978) y otros llaman memorización mecánica, que no llega a constituir aprendizaje significativo; pues, aunque de hecho las respuestas sean correctas, el alumno no sabe extrapolarlas a otro entorno o situación distinta a la aprendida.

La encuesta que figura a continuación como Anexo I permite un sondeo de los esquemas conceptuales que tienen los alumnos sobre la respiración celular. Con ella se han perseguido los siguientes objetivos:

19) Detectar las representaciones de los alumnos sobre el proceso de respiración celular como fuente de energía de los seres vivos. $\left.2^{\circ}\right)$ Detectar las representaciones sobre el lugar donde se lleva a cabo el proceso respiratorio y si éste es confundido con el simple intercambio de gases.

39) Detectar el grado de identificación de la respiración celular con una reacción química de la materia orgánica, para la que se necesita oxígeno y se desprende dióxido de carbono como producto de desecho.

$\left.4^{\circ}\right)$ Detectar las ideas que tienen los alumnos sobre cl origen de la materia organica que se quema en la respiración; si ésta es adquirida por ingestión, como hacen los animales, o bien, es fabricada por ellos mismos como hacen los vegetales verdes.

$5^{\circ}$ ) Investigar la consistencia de cstas representaciones comparando las respuestas dadas por los alumnos a los distintos ítems.

\section{TRATAMIENTO DE LOS RESULTADOS}

A las respuestas a cada una de las cuestiones que plantea la encuesta se les ha aplicado un $\mathrm{X}^{2}$, separadamente para el caso de animales y para el caso de vegetales, con objeto de saber, si las diferencias entre las frecuencias obtenidas en $1^{\circ}, 3^{\circ}$ y COU para cada una de las preguntas llegan a ser significativas, lo que reflejaría un cambio en los esquemas conceptuates de los alumnos a lo largo de los niveles.

$$
\mathrm{X}^{2}=\sum_{\mathrm{ij}} \frac{\left(\mathrm{Oij}-\mathrm{Eij}^{2}\right.}{\mathrm{Eij}_{\mathrm{ij}}} \quad \begin{aligned}
& \mathrm{O}=\text { Frecuencias observadas } \\
& \mathrm{E}=\text { Frecuencias esperadas }
\end{aligned}
$$

\section{LOS RESULTADOS Y SU ANÁLISIS}

Se han contabilizado solamente las respuestas dadas con un margen de seguridad superior a 5, suponiendo éstas un $95 \%$ del total de la muestra y siendo los resultados los siguientes:

$1^{\text {a }}$ cuestión: « ¿Respiran los animales? ¿Respiran los vegetales?»

Los porcentajes obtenidos de respuestas correctas (Sí, los animales. Sí, los vegetales) fueron los siguientes:

\begin{tabular}{|c|c|c|}
\hline $1^{\circ}$ de BUP & $3^{\circ}$ de BUP & $\mathrm{COU}$ \\
\hline Anim. Veg. & Anim. Veg. & Anim. Veg. \\
\hline $100 \% \quad 100 \%$ & $100 \% \quad 100 \%$ & $100 \% \quad 100 \%$ \\
\hline
\end{tabular}

El 100\% de los alumnos de los tres niveles han respondido correctamente y aparentemente no tienen duda de ello, aunque podría darse el caso de ser un conocimiento 
declarativo (Haswen 1986) repitiendo fragmentos de lo aprendido, sin ser capaces de aplicarlo a la resolución de un problema de la vida cotidiana (conocimiento procedimental que muestra aprendizaje significativo). Por ello, se pasa a continuación a investigar lo que entienden por tespiración, puesto que en estudios ya realizados (Stavy et al. 1987) obtuvieron respuestas en las que se contemplaba la fotosíntesis como un tipo de respiración, señalándo en algunos casos que era una respiración inversa.

$2^{ \pm}$cuestión: « ¿La respiración consiste solamente en un intercambio de gases con el medio ambiente en animales y/o en vegetales?»

Los porcentajes de respuestas correctas (No, en animales. No, en vegetales) fueron los siguientes:

\begin{tabular}{|c|c|c|}
\hline $1^{9}$ de BUP & $3^{9}$ de $B U P$ & $\mathrm{COU}$ \\
\hline Anim. Veg. & Anim. Veg. & Anim. Veg. \\
\hline $47 \%$ & $42 \%$ & $52 \%$ \\
\hline
\end{tabular}

Como puede apreciarse por los porcentajes, parte de los alumnos encuestados presentan la idea alternativa de que la respiración consiste solamente en un intercambio de gases con el medio ambiente, persistiendo además esta idea a lo largo de los tres niveles. La respuesta obtenida puede estar justificada si tenemos en cuenta que la pregunta está formulada desde un punto de vista perceptivo «Lo que se ve es lo que se cree», siendo ésta una de las causas que señalan Osborne (1983) Driver y Erikson (1983) como origen de las ideas previas: «El pensamiento está dominado por la percepción».

La aplicación del $\mathrm{X}^{2}$ indica que no hay significación ni en las respuestas correspondientes a animales ni erı las correspondientes a vegetales entre los niveles de $1^{\frac{1}{2}}, 3^{2}$ y COU, tratándose, por tanto, de una idea alternativa que persiste en los tres niveles.

$3^{\text {a }}$ cuestión: «La verdadera respiración ocurre en las células y para ello se necesita oxígeno y se desprende dióxido de carbono".

Los porcentajes de respuestas correctas (Sí, en animales. Sí, en vegetales) han sido los siguientes:

\begin{tabular}{|cc|cc|cc|}
\hline \multicolumn{2}{|c|}{$\mathfrak{1}^{2}$ de BUP } & \multicolumn{2}{|c|}{$3^{2}$ de BUP } & \multicolumn{2}{c|}{ COU } \\
Anim. & Veg. & Anim. & Veg. & Anim. & Veg. \\
$100 \%$ & $53 \%$ & $96 \%$ & $54 \%$ & $96 \%$ & $76 \%$ \\
\hline
\end{tabular}

Gran parte de los alumnos encuestados piensan que los animales son distintos de los vegetales en cuanto a la respiración celular. Esta idea alternativa se mantiene sobre todo en los cursos de BUP subsanándose en parte en el nivel de COU. Se aprecia además poca coherencia en los razonamientos, pues una gran mayoría contesta afirmativamente a la $2^{\underline{a}}$ y a la $3^{\frac{a}{}}$ pregunta a la vez, siendo ambas excluyentes. Estos resultados corroboran las obtenidas por Astudillo y Gene (1984) en su trabajo sobre: «Errores conceptuales en Biología. La fotosíntesis de las plantas verdes».

Así mismo, Driver, Guesne y Tiberghien (1985) señalan como uno de los rasgos generales que presentan las ideas alternativas el hecho de que «consideran solo aspectos limitados de una situación dada, lo que dificulta la comprensión de interacciones entre varios elementos". Un aspecto particular de esta atención limitada es la dificultad para percibir situaciones de equilibrio dinámico, como pueden ser muchas reacciones metabólicas.

$\mathrm{La}$ aplicación del $\mathrm{X}^{2}$ indica que no existe significatividad en cuanto a los resultados obtenidos en los tres niveles estudiados.

$4^{\frac{a}{2}}$ cuestión: Está planteada con el objetivo de comprobar si los alumnos relacionan la respiración como fuente productora de energía para las células. «La respiración es un proceso para que las células produzcan energía por medio de una combustion"».

Los porcentajes de respuestas correctas ( $\mathrm{Sí}$, en animales. Sí, en vegetales) han sido los siguientes:

\begin{tabular}{|c|c|c|}
\hline$I^{o}$ de BUP & $3^{\circ}$ de BUP & $\mathrm{COU}$ \\
\hline Anim. Veg. & Anim. Veg. & Anim. Veg. \\
\hline $60 \% \quad 56 \%$ & $90 \%$ & $90 \% \quad 59 \%$ \\
\hline
\end{tabular}

Nuevamente aparecen ideas alternativas; en $1^{\circ}$ de BUP, un $40 \%$ del grupo no relaciona la respiración como fuente energética ni en animales ni en vegetales. En los grupos de $3^{\circ}$ y COU, esta representación decrece su porcentaje en animales, pero persiste en vegetales.

Dreyfus y Jungwirth (1988) ponen de manifiesto la idea alternativa de que sólo algunas células producen energía y fabrican proteínas. Algo semejante ocurre con Gayford (1986) en su artículo: «Some aspects of the problems of teaching about energy in school biology", donde la respiración no se identifica como proceso productor de energía.

Según la respuesta obtenida en esta cuestión, en los niveles de $3^{\circ}$ y COU se observa que los alumnos dan un tratamiento muy diferente en cuanto a la producción de energía en la célula animal de la célula vegetal. ¿Será porque identifican la respiración en vegetales con el proceso de fotosíntesis? En los siguientes ítems se investiga esta cuestión.

La aplicación del $\mathrm{X}^{2}$ muestra nuevamente que no hay significatividad entre los niveles de $1^{\circ}, 3^{\circ}$ y COU, siendo por tanto persistente esta representación a lo largo deI bachillerato y COU. 
$5^{a}$ cuestión: Es una ampliación de la pregunta número 3. Introduzco aquí el concepto de materia orgánica como sustrato que «se quema» en Ia respiración celtalar. Además en esta pregunta y la siguiente entro en relación con el concepto de nutrición autótrofa y heterótrofa, en el momento en que planteo la pregunta como: «La materia orgánica y el oxígeno que toman los seres vivos son llevados hasta las células para intervenir en la respiración y expulsar dióxido de carbono.»

Los porcentajes de respuestas correctas ( $S i ́$, en animales. No, en vegetales) han sido los siguientes:

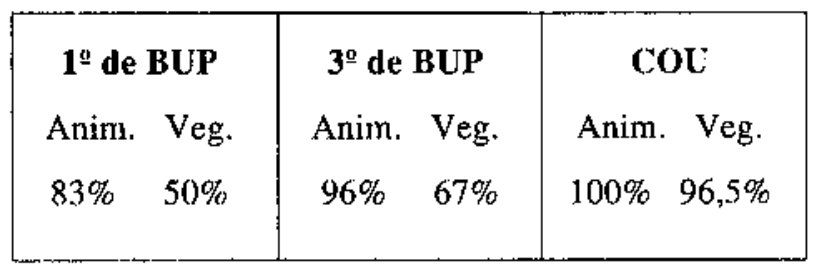

Resulta muy significativo en la observación de estos porcentajes como el error conceptual de que los vegetales toman la materia orgánica, va decreciendo desde un $50 \%$ en $1^{\circ}$ de BUP, un $33 \%$ en $3^{\circ}$ hasta llegar a un $3,5 \%$ en COU. La posible explicación que se le puede dar a estos datos sea quizás la falta de conceptos claros a nivel de $1^{\underline{Q}}$ de BUP de lo que es la materia orgánica, con lo que pretendo corroborar la idea que Pedro Cañal y Soledad García (1987) sacan a la luz en su artículo «I a nutrición vegetal, un año después. Un estudio de caso de $7^{\circ}$ de EGB», donde dicen textualmente: «En general estos alumnos carecen de conceptualizaciones adecuadas sobre lo que es inorgánico u orgánico...»

Aplicado el $\mathrm{X}^{2}$ no resulta significativo en animales ni en vegetales, aunque en estos últimos queda muy cercano al límite de significatividad.

$6^{\text {a }}$ cuestión: Esta pregunta es la complementaria a la anterior; se da la otra versión, redactándola: «No ingieren la materia orgánica sino que la fabrican...». Por tanto, la comparación de las respuestas obtenidas en uno y otro caso nos va a permitir medir la consistencia que tienen estas ideas en nuestros alumnos.

Los porcentajes de respuestas correctas (No, en animales. Sí, en vegetales) han sido los siguientes:

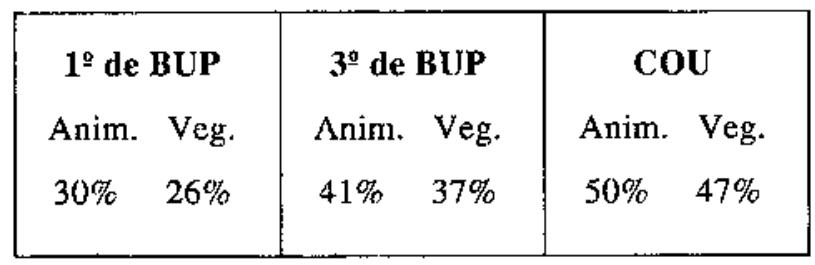

Por los porcentajes obtenidos se puede deducir que incluso a nivel de COU la mitad de los alumnos contesta incorrectamente. Este resultado viene a coincidir con lo que Bell (1985) señala en su artículo: «Students'ideas about plant nutrition: what are they?» los alumnos po- seen concepciones alternativas sobre la forma en que los vegetales obtienen la comida, así como, a otros conceptos derivados de la fotosíntesis respecto a intercambios gaseosos, producción de energía, etc.

Otros estudios llevados a cabo por Wandersee (1983, 1985) en Estados Unidos, Stavy et al. (1987) en Israel, y Bell y Brook (1984) en el Reino Unido han mostrado la dificultad que tienen los adolescentes por comprender la fotosíntesis, y al preguntarles de dónde procede el alimento de las plantas, la mayoría contestaron que del suelo. La aplicación del $\mathrm{X}^{2}$ muestra nuevamente que no existe significatividad entre las respuestas dadas en los tres niveles ni en el caso de animales ni en el de vegetales.

$7^{2}$ cuestión: Como conclusión a la encuesta planteada, quise indagar someramente, los conceptos que nuestros alumnos tienen sobre el tema a nivel microscópico. Este es el objeto de las preguntas $n^{\circ} 7$ y 8 donde introduzco «mitocondrias» $\mathrm{y}$ «cloroplastos», partiendo de la hipótesis de que el alumnado no delimita claramente el papel que desempeñan cada uno de estos orgánulos mencionados; con ellos «juego» en estas dos últimas preguntas: «Las mitocondrias son los orgánulos más implicados en el proceso de respiración de las células»

Los porcentajes de respuestas correctas (Sí, en animales. Sí, en vegetales) obtenidas han sido los siguientes:

\begin{tabular}{|c|c|c|}
\hline $1^{2}$ de BUP & $3^{o}$ de BUP & $\mathrm{COU}$ \\
\hline Anim. Veg. & Anim. Veg. & Anim. Veg. \\
\hline $93 \% \quad 40 \%$ & $78 \% \quad 48 \%$ & $100 \%$ \\
\hline
\end{tabular}

8 cuestión: «¿Son los cloroplastos los orgánulos implicados en el proceso de la respiración celular en animales y/o en vegetales?»

Los porcentajes de respuestas correctas (No, en animales. No, en vegetales) obtenidas han sido los siguientes:

\begin{tabular}{|cc|cc|cc|}
\hline \multirow{2}{*}{$1^{2}$ de BUP } & \multicolumn{2}{|c|}{$3^{2}$ de BUP } & \multicolumn{2}{c|}{ COU } \\
Anim. & Veg. & Anim. & Veg. & Anim. & Veg. \\
$96,7 \%$ & $33,4 \%$ & $97 \%$ & $18 \%$ & $100 \%$ & $48 \%$ \\
\hline
\end{tabular}

Se aprecia un nuevo error conceptual y además de gran persistencia. Se trata, de que en un gran porcentaje los alumnos piensan que los vegetales no usan las mitocondrias para la respiración celular (cuestión $n^{2} 7$ ) y que esta función se lleva a cabo en los cloroplastos (cuestión $\mathrm{n}^{\circ} 8$ ). Nuevamente se ponen de manifiesto ideas alternativas que vienen a corroborar trabajos citados con anterioridad (Astudillo y Gené 1984) y otros, llegando a la conclusión de que los alumnos piensan que el proceso de 
la fotosíntesis en las plantas verdes equivale al de la respiración en animales.

$\mathrm{El} \mathrm{X}^{2}$ aplicado a estas respuestas sale nuevamente con significatividad negativa.

\section{CONCLUSIONES Y PROPUESTAS}

Se ha podido observar como en ninguno de los casos en que se ha aplicado el $\mathrm{X}^{2}$ las diferencias de las respuestas dadas entre los tres niveles de $1^{2}, 3^{a}$ y COU eran significativas, lo que indicaría un mal planteamiento de la asignatura de Ciencias Naturales a lo largo del bachikletato y COU, no haciendo progresar los esquemas conceptuales de los alumnos. La instrucción escolar, no sólo no ha modificado las ideas alternativas, sino que las ha reforzado. Se entablaría en este momento toda la controversia que đesđe años atrás se viene poniendo de manifiesto sobre el modo de utilizar las representaciones y que Giordan (1989) recoge en su artículo: «Representacio- nes sobre la utilización de las representaciones». ¿Hay que trabajar CON eltas, en CONTRA de ellas o bien a TRAVES de ellas? Sea como sea, y tal como sigue citando: «Un mejor conocimiento de la puesta en marcha de las representaciones puede contribuir eficazmente a la elección de las condiciones de aprendizaje». Aboga también, por la no destrucción de las representaciones mientras no se disponga de estrategias que permitan obtener al alumno una explicación alternativa más lógica y coherente que la suya.

Existe además, una amplia evidencia de que algunas de estas ideas resultan muy difíciles de cambiar y que, a pesar de la instrucción escolar, como es en este caso, persisten en la edad adulta (Lucas 1987).

Se propone una reestructuración de estos temas que facilite la construcción de un modelo interpretativo global, del abandono del modelo clásico y de un estudio desconectado de los distintos aparatos y sistemas, prescindiendo de la gran canticiad de detalies y de «nombres» con los que se metrallea a los alumnos, habiendo estudiado de antemano o a posteriori el nivel celular como un «ente» aislado.

\begin{abstract}
ANEXO I
Lec despacio cada una de estas cuestiones y después de rerlexionar, marca con una $\mathrm{X}$ aquellos recuadros que creas correctos en animales, en vegetales o en ambos. Esta prueba es anónima, por lo tanto no va a servir para calificarte pero es importante que pienses antes de contestar. Si no lo sabes o no tienes opinión déjalo en blanco. En cada recuadro señala de 0 a 10 el grado de seguridad con que das cada respuesta (cero, ninguna seguridad y diez, máxima seguridad).
\end{abstract}

\begin{tabular}{|c|c|c|}
\hline & ANIMALES & $\begin{array}{l}\text { VEGETALES } \\
\text { VERDES }\end{array}$ \\
\hline Respiran & & \\
\hline $\begin{array}{l}\text { La respiración consiste solo en un intercambio de gases con el medio } \\
\text { ambiente. }\end{array}$ & & \\
\hline $\begin{array}{l}\text { La verdadera respiración ocurre en las células de todos los orga- } \\
\text { nismos para lo cual se necesita el oxígeno y se desprende dioxido } \\
\text { de carbono. }\end{array}$ & & \\
\hline $\begin{array}{l}\text { La respiración es un proceso para quelas células produzcan energía } \\
\text { por medio de una combustion. }\end{array}$ & & \\
\hline $\begin{array}{l}\text { La materia orgánica y el oxígeno que toman los seres vivos son } \\
\text { llevados hasta las células para intervenir en la respiración y expul- } \\
\text { sar dioxido de carbono. }\end{array}$ & & \\
\hline $\begin{array}{l}\text { No ingieren la materia orgánica sino que la fabrican guardando en } \\
\text { ella la energia que quedará libre en el proceso de respiracicin. }\end{array}$ & & \\
\hline $\begin{array}{l}\text { Las mitocondrias son los orgánulos más implicados en el proceso } \\
\text { de respiración de las células. }\end{array}$ & & \\
\hline $\begin{array}{l}\text { Los cloroplastos son los orgánulos más implicados en el proceso de } \\
\text { respiración de las células. }\end{array}$ & & \\
\hline
\end{tabular}




\section{REFERENCIAS BIBLIOGRÁFICAS}

ASTUDILLO, H. y GENE, A.M., 1984. Errores conceptuales en biología. La fotosintesis de las plantas verdes. Enseñanza de las Ciencias, 2(1), pp. 15-16.

BFI.L, B., 1985. Students'ideas about plant nutrition. What are they?, Journal of Biological Education, 19 (3).

BELL, B. y BROOK, A., 1984. Aspects of secondary student's understanding of plant nutrition. (Children l.earning in Science Project, Leeds Lniversitat).

CAÑAL, P., 1987. La nutrición vegetal, un año después. In estudio de caso de $7^{\mathrm{a}}$ de FGB, Investigación en la Escuela, 3, pp. 55-60.

CARRASCOSA, J. 1987. Tratamiento didactico en la Enseñanza de las Ciencias de los errores conceptuales. (Tesis doctoral. Universidad de Valencia).

DREYPUS, A. y JUNGWIRTH, E., 1988. The cell concept of 10th graders: curricular expectations and reality, International journal of Science Education, Vol.10(2), pp. 221-229.

DRIVER, R, GUESNE, E.y TIBERGHIEN, A, 1985. Children's ideas in science. (Philadelphia: Open University Press).

DRIVER, R., 1986. Psicología cognoscitiva y esquemas conceptuales de los alumnos, Enseñanza de las Ciencias, 4.

GAYFORD, C.G., 1986. Some aspects of the problems of teaching about energy in school biology. European Journal of Science Education, 8 (4), pp. 443-450.
GIORDAN. A., 1985. Interés dídáctico de los errores de los alumnos, Enseñanza de las Ciencias, 3(1), pp. 11-17.

GIORDAN, A., 1988, Losorigenes del saber. (Diada: Sevilla).

GIORDAN, A., 1989. Representaciones sobre la utilizacion didactica de las representaciones, Enseñanza de las Ciencias, 7(1), pp. 53-62.

HEWSON, P., 1981. A conceptual change approach to learning Science. European Journal of Science Education, $3(4)$, pp. 383-396.

JIMÉNEZ AI.FIXANDRE, M.P., 1987. Preconceptos y esquemas conceptuales en Biología, Enseñanza de las Ciencias, $5(2)$.

LUCAS, A.,1987. Public Knowledge of Biology, Journal of Biological Education, 21(1), pp. 41-45.

SFRRANO, T,, 1986. Representaciones de los alumnos en Biología: Estado de la cuestion y problemas de su investigazción en el aula. IV Jornadas de Estudio sobre la Investiga. ción en la Escuela, pp. 157-162.

SERRANO. T., 1988. Las ideas de los alumnos en el aprendizaje de las Ciencias. Apuntes IEPS, $n^{\circ} 47$. (Ed. Narcea: Madrid).

STAVY, R. et aI., 1987. How estudents aged 13-15 understand photosynthesis, International Journal of Science eduction, 9(1), pp. 105-115. 